http://dx.doi.org/10.11606/issn.2238-6149.v28i1pi-ii

\title{
Terapia Ocupacional e os Desafios da Pesquisa Qualitativa
}

\section{Occupational Therapy and the Challenges of Qualitative Research}

\author{
Elisabete Ferreira Mângia*
}

A importante expansão e reconhecimento internacional das abordagens qualitativas, que vem ocorrendo na última década, a multiplicidade de periódicos e campos de pesquisa, a sofisticação das metodologias e as suas novas exigências formais e critérios de qualidade, desafiam os pesquisadores nacionais da Terapia Ocupacional.

No Brasil, essa expansão é mais recente e também pode ser percebida pelo interesse de editores na publicação de livros, nesse campo, que trouxeram importantes contribuições de autores internacionais e tendências da pesquisa qualitativa. A abundância e o fácil acesso a fontes seguras propicia recursos para o amadurecimento de pesquisadores já experientes e para a formação consistente de jovens pesquisadores.

Para a Terapia Ocupacional Nacional o desafio se mostra mais forte s e a valiarmos que, a pesar do significativo aumento do volume de publicações e formação acadêmica dos pesquisadores, ainda estamos distantes de atingir um patamar satisfatório para as proposições de investigações qualitativas, desenhos e utilização mais rigorosa de suas metodologias.

O ainda pouco diálogo com a produção internacional da área, que apresenta atualmente um surpreendente patamar de qualidade, fragiliza a possibilidade de avanços necessários para a melhor qualificação da p rodução n acional no cenário internacional.

A literatura internacional mostra claramente o esforço que os campos da Enfermagem e a própria Terapia Ocupacional tem empreendido para sustentar e situar suas posições no campo da pesquisa, em especial da pesquisa qualitativa em saúde e, ao mesmo tempo, atender as demandas sempre crescente das exigências avaliativas dos periódicos e órgãos de financiamento.

Também caracterizam esse processo o longo debate sobre as Práticas Baseadas em Evidências e a própria ampliação do conceito de evidências que hoje abarca as evidências da prática clínica e os estudos qualitativos. Soma-se a isso as diversas tendências e modelagens para a produção de revisões de literatura como os modelos da revisão integrativa, da scoping review e das metassinteses qualitativas.

Editores experientes são unanimes em apontarem as necessidades de aprimoramento do desenvolvimento e modelagem da pesquisa qualitativa e mostram que esse desafio é coletivo e deve envolver múltiplos atores: pesquisadores, professores e alunos, além dos profissionais voltados para a qualificação das práticas clínicas.

Defendem a necessidade do aprimoramento da escrita acadêmica para que os textos de pesquisa ganhem maior consistência interna e possam superar posturas, muitas vezes avaliadas como superficiais. A importância do detalhamento das abordagens teóricas e da forma como cada pesquisador as utiliza, a descrição minuciosa da elaboração de categorias que muitas vezes são apontadas apenas como "emergentes" sem que o leitor possa compreender como "emergiram", dentre outros fatores implicados na escrita da pesquisa, se torna fundamental.

O cuidado na apresentação de resultados obtidos e sua posterior discussão, em relação primeiramente as questões de pesquisa e seus objetivos, a atenção no trabalho com a bibliografia, especialmente quando há intenção de comparar dados

*Editora da Revista de Terapia Ocupacional da USP, Docente do Curso de Terapia Ocupacional da Faculdade de Medicina da Universidade de São Paulo. 
obtidos em um estudo novo com estudos anteriores. O cuidado na organização e clareza da escrita também é um elemento fundamental à reflexão qualitativa, e delas dependem a possibilidade de traduzir com profundidade a reflexão buscada em cada estudo e em especial sua capacidade de dialogar com estudos anteriores e fazer avançar o campo de interesse no qual se situa.

Esse conjunto de aspectos, aparentemente simples, somado ao conhecimento mais rigoroso das tendências da pesquisa qualitativa e suas múltiplas possibilidades, podem definir filiações mais precisas e orientar novos pesquisadores a adentrarem nesse campo, já com mais maturidade.

Atualmente sabemos ser ingênuo separar as abordagens qualitativas das quantitativas, como se esta separação ainda persistisse tão fortemente como no passado.

O uso de metodologias combinadas e bem articuladas qualifica a pesquisa e tem sido adotado, cada vez mais, pelos pesquisadores, atentos aos desafios atuais. As metodologias qualitativas ganharam muita relevância e destaque no campo da saúde. Portanto é necessário o aprimoramento e cuidado cada vez mais atento com suas práticas, pois ainda há um longo caminho a percorrer em nosso cenário.

Assim, os pesquisadores e, em especial os docentes, da Terapia Ocupacional devem preocupar-se em como melhorar a sua própria formação em metodologias de pesquisa e em como levar esse desenvolvimento aos alunos já desde a graduação. Essa tarefa não é facilmente realizável tendo em vista um cenário de ensino e práticas ainda muito ancorados em aproximações teóricas com outras áreas e na cultura oral. Soma-se a isso a precariedade das condições de trabalho da maior parte dos grupos docentes vinculados às instituições de ensino públicas e que deveriam assumir mais fortemente sua missão no desenvolvimento da pesquisa e da formação pós-graduada.

Sim, estamos ampliando a produção nacional, mas sustentar esse processo requer de todos atenção para as crescentes exigências de qualificação. 